\title{
AMPLIFIKASI IN VITRO DAN IN VIVO FRAGMEN 0,4 KB D-LOOP
} \section{mIDNA SAMPEL FORENSIK}

\author{
Mukhammad Asy'ari*, A. Saifuddin Noer** \\ * Laboratorium Biokimia jurusan Kimia FMIPA UNDIP Semarang \\ ** Laboratorium Rekayasa Genetika PAU Bioteknologi ITB Bandung
}

\begin{abstract}
ABSTRAK
Daerah DNA mitokondria (mtDNA) manusia yang mempunyai tingkat polimorfisme tertinggi adalah D-loop. Urutan nukleotida D-loop mtDNA dapat dijadikan alat untuk menentukan identitas genetik seseorang. Saat ini aplikasinya banyak digunakan untuk memecahkan kasus-kasus di bidang forensik. Isolasi fragmen 0,4 kilobasa $(\mathrm{kb}) \mathrm{D}$-loop mtDNA dapat dilakukan dengan mengekstrak mtDNA dari dalam sel, kemudian menggandakan (amplifikasi) mtDNA secara in vitro dengan metoda Polymerase Chain Reaction (PCR) dan secara in vivo dengan metoda Kloning. Pada penelitian ini telah berhasil diamplifikasi secara in vitro fragmen 0,4 kb mtDNA sampel forensik dengan metoda PCR menggunakan primer M1 (5'CACCATTAGCACCCAAAGCT-3') dan M2 (5'GATTTCAC GGAGGATGGTG-3') dan secara in vivo dengan metoda kloning menggunakan vektor $p$ GEM-T dalam sel inang Eschericia coli JM 109. Identifikasi hasil PCR dilakukan dengan metoda elektroforesis gel agarosa 1\% menggunakan pewarna fluorisen Etidium Bromida. Sedangkan sel rekombinan hasil kloning diseleksi menggunakan media selektif mengandung antibiotik ampisilin dan zat pewarna kultur rekombinan yaitu X-gal dan IPTG sebagai indusernya. Identifikasi plasmid rekombinan yang mengandung fragmen 0,4 kb D-loop mtDNA dilakukan menggunakan enzim restriksi Pst I. Hasil kloning diperoleh jumlah koloni putih (sel rekombinan) : biru (sel non rekombinan) adalah $2: 1$. Hasil analisis restriksi enzim PstI pada plasmid rekombinan diperoleh fragmen berukuran 3,4 kb, hal ini menunjukkan bahwa DNA insert berukuran 0,4 kb sesuai dengan fragmen mtDNA hasil PCR. Plasmid rekombinan selanjutnya digunakan pada penelitian berikutnya, yaitu penentuan urutan nukleotida dengan metode sekuensing sehingga dapat diketahui identitas genetika dari sampel forensik yang dianalisis.
\end{abstract}

Kata kunci: D-loop mtDNA, PCR, kloning, enzim PstI, sampel forensik

\section{IN VITRO AND IN VIVO AMPLIFICATION OF 0,4 KB D-LOOP mtDNA FRAGMENT OF FORENSIC SAMPLE}

\begin{abstract}
D-loop is the highest polymorphism region on Human mitochondrial DNA (mtDNA). Nucleotides sequence of mtDNA D-loop usually using as evidence genetic identities. Recently, applied of D-loop region to solved a riddle forensic case. Isolation of 0,4 kilobase ( $k b$ ) mtDNA D-loop fragments were done trough extraction of mtDNA from the cells, then amplified of mtDNA trough in vitro methods that is Polymerase Chain Reaction (PCR) and in vivo methods that is cloning. In this research have successed in vitro amplified $0,4 \mathrm{~kb}$ mtDNA $D$-loop fragment from forensic samples. PCR reaction using primers: $M 1$ (5'CACCATTAGCACCCAAAGCT-3') and M2 (5'GATTTCAC GGAGGATGGTG-3'), whereas cloning using pGEM-T vector and Eschericia coli JM 109 as host cell. PCR product identified by agarose $1 \%$ electrophoresis using fluoriscent dye that is ethydium bromide. Whereas, to selection recombinat cells using selective media that contains ampicilin and culture dye that is X-gal and IPTG as inducer. To identified recombinat cells contains $0,4 \mathrm{~kb}$ mtDNA D-loop fragments using restriction enzyme that is PstI. The result of cloning are white (recombinat cells) and blue (non recombinant cells) colony with equal $2: 1$. The result of restriction analysis of PstI enzyme on recombinant plasmid is 3,4 $\mathrm{kb}$ fragment contain 0,4 $\mathrm{kb}$ insert DNA is appropriate with mtDNA fragment of PCR product. Recombinant plasmid using for further research to determine nucleotides sequence by sequencing methods to understand genetic identities of forensic samples.
\end{abstract}

Keyword : mtDNA D-loop, PCR, cloning, PstI enzyme, forensic sample 


\section{PENDAHULUAN}

D-loop merupakan daerah pada DNA mitokondria (mtDNA) yang mempunyai laju evolusi lima kali lebih cepat dibandingkan daerah lain pada DNA mitokondria (Aquadro dan Greenberg, 1983; Cann, 1987). Pada tahun 1991 tingkat homologi urutan nukleotida fragmen 0,4 kb D-loop mtDNA (posisi nukleotida 16.042-16388) digunakan untuk menentukan hubungan segaris keturunan ibu (maternal) antar individu (Orego dan King, 1990), yang selanjutnya banyak digunakan untuk memecahkan kasus-kasus di bidang forensik.

Barang bukti organik (organic evidence material) pada kasus forensik biasanya ter-dapat dalam jumlah sangat sedikit, misalnya sehelai rambut, percikan darah yang kering dan kotor, serpihan sel otot atau setetes keringat, sehingga tidak mungkin dapat diidentifikasi dengan cara konvensional (Moore, dan Isenberg, 1999). Proses pembuktian hubungan maternal pada kasus tersebut dilakukan identifikasi secara genetika melalui beberapa tahap yaitu: ekstraksi mtDNA dari sampel forensik, amplifikasi in vitro dengan metode $\mathrm{PCR}$, amplifikasi in vivo dan skrining mtDNA dengan metode kloning dan penentuan urutan nukleotida dengan metode sekuensing. Kesulitan yang sering timbul adalah pada tahap ekstraksi dan amplifikasi mtDNA. Hal ini disebabkan kondisi sampel yang sudah rusak dan sangat sedikit jumlahnya. Keberhasilan dalam mengektraksi dan mengamplifikasi fragmen mtDNA sangat mempengaruhi proses selanjutnya yaitu sekuensing.

Penelitian ini bertujuan untuk mengatasi permasalahan tersebut di atas yaitu dengan mengisolasi fragmen $0,4 \mathrm{~kb}$ D-loop mtDNA sampel forensik secara efektif dan mengamplifikasinya dengan metode PCR dan kloning. Penelitian ini merupakan tahap awal, tapi sangat penting dan menentukan dari rangkaian proses identifikasi genetika dalam pembuktian kasus forensik.

\section{BAHAN DAN METODE}

Tahapan kerja dalam penelitian ini meliputi: (1) penyiapan templat mtDNA, (2) amplifikasi templat mtDNA secara in vitro dengan metode PCR dan (3) kloning fragmen hasil PCR dengan menggunakan kit vektor pGEM-T dan sel inang E.coli JM 109.

\section{Penyiapan templat mtDNA}

Sampel yang digunakan adalah tiga sampel forensik (diperoleh dari Laboratorium Forensik Fak. Kedokteran UNPAD Bandung). Penyiapan sampel dilakukan dengan menimbang $1 \mathrm{mg}$ sampel kemudian dicuci dengan bufer TE pH 8 sampai dihasilkan pelet ber-warna putih (Sambrook et al., 1989). Lisis dilakukan dengan mencampurkan pelet sampel dengan $40 \mu \mathrm{L}$ bufer lisis $10 \mathrm{X}$ dan ditambahkan $\mathrm{ddH}_{2} \mathrm{O}$ steril hingga volume $400 \mu \mathrm{L}$. Campuran reaksi diinkubasi pada suhu $55^{\circ} \mathrm{C}$ selama 1 jam (Waterbath-Grant Instrmnt) dan dilanjutkan pada suhu $95^{\circ} \mathrm{C}$ selama 5 menit. Kemudian disentrifugasi (Eppendorf 5417C) pada 20.000 g selama 3 menit, diambil supernatan yang selanjutnya digunakan sebagai templat reaksi PCR (Noer et al., 1994).

\section{Amplifikasi in vitro fragmen 0,4 kb mtDNA}

Amplifikasi in vitro fragmen $0,4 \mathrm{~kb}$ D-loop mtDNA menggunakan sepasang primer yaitu M1 (5'CACCATTAGCACCCAAAGCT-3') 
dan M2 (5'GATTTCACGGAGGATGGTG-3').

Proses PCR dilakukan sebanyak 30 siklus, dengan tahap denaturasi pada suhu $94^{\circ} \mathrm{C}$ selama 1 menit, annealing pada suhu $50^{\circ} \mathrm{C}$ selama 1 menit dan tahap extension pada suhu $72^{\circ} \mathrm{C}$ selama 1 menit (Perkin Elmer, 1992).

Hasil PCR dianalisis melalui elektro-foresis gel agarosa $1 \%(\mathrm{~b} / \mathrm{v})$. Marker DNA standar yang digunakan adalah pUC19/Hinf I.

Pemurnian hasil PCR dilakukan dengan metode presipitasi etanol (Sambrook et al., 1989). Konsentrasi DNA dihitung berdasarkan hasil perbandingan intensitas fluorisen dari pita sampel dengan pita marker. Selanjutnya DNA hasil pemurnian tersebut siap diligasikan ke dalam vektor pGEM-T.

\section{Kloning}

Prosedur kerja kloning dibagi dalam 4 tahap yaitu: (1) ligasi fragmen hasil PCR ke dalam vektor pGEM-T, (2) pembuatan sel kompeten, (3) transformasi sel inang dengan vektor plasmid rekombinan (4) seleksi dan isolasi plasmid rekombinan.

(1). Ligasi hasil PCR dengan vektor pGEM-T

Reaksi ligasi pGEM-T dan 60 ng fragmen hasil PCR murni dilakukan menggunakan kit pGEM-T. Hasil ligasi ini merupakan plasmid pGEM rekombinan yang siap digunakan untuk mentransformasi sel inang E.coli JM 109 (Promega, 1998).

(2). Pembuatan sel kompeten E.coli JM 109

Metode yang digunakan dalam pembuatan sel kompeten merujuk pada metode Cohn (Sambrook et al., 1989).
(3). Tranformasi sel inang E.coli JM109

Sel E.coli JM109 kompeten selanjutnya ditranformasi oleh plasmid pGEM rekombinan, dengan metode heat shock (Sambrook et al., 1989). Hasil transformasi ditumbuhkan pada media SOC (Promega, 1998), kemudian ditumbuhkan kembali di atas media padat selektif LB (mengandung ampicillin, X-gal dan IPTG) pada suhu $37^{\circ} \mathrm{C}$ selama 14-18 jam (Promega, 1998; Sambrook et al., 1989).

(4). Seleksi dan isolasi plasmid rekombinan Seleksi dilakukan berdasarkan perbedaan warna koloni sel yang tumbuh, koloni warna putih (plasmid rekombinan) dan biru (non rekombinan). Isolasi plasmid rekombinan dilakukan dengan metode maniatis termodifikasi (Sambrook et al., 1989). Pemurnian plasmid rekombinan dilakukan dengan metode presipitasi etanol dan analisis hasil menggunakan elektroforesis agarosa $1 \%$, pemotongan plasmid rekombinan menggunakan enzim PstI dan marker DNA $\lambda /$ HindIII.

\section{PEMBAHASAN}

\section{Fragmen mtDNA hasil PCR}

Hasil PCR dari tiga sampel (S1, S2, S3) diperoleh fragmen mtDNA berukuran sekitar $400 \mathrm{pb}(0,4 \mathrm{~kb})$, ditunjukkan oleh satu pita yang terletak di antara pita 517 dan 396 pb pada DNA standar pUC/HinfI (M), seperti tercantum pada gambar 1. Hasil ini sesuai prediksi, yaitu fragmen $442 \mathrm{pb}$ daerah D-loop mtDNA pada posisi 15.978-16.419 (Anderson et al, 1981; Aquadro dan Greenberg, 1983). 


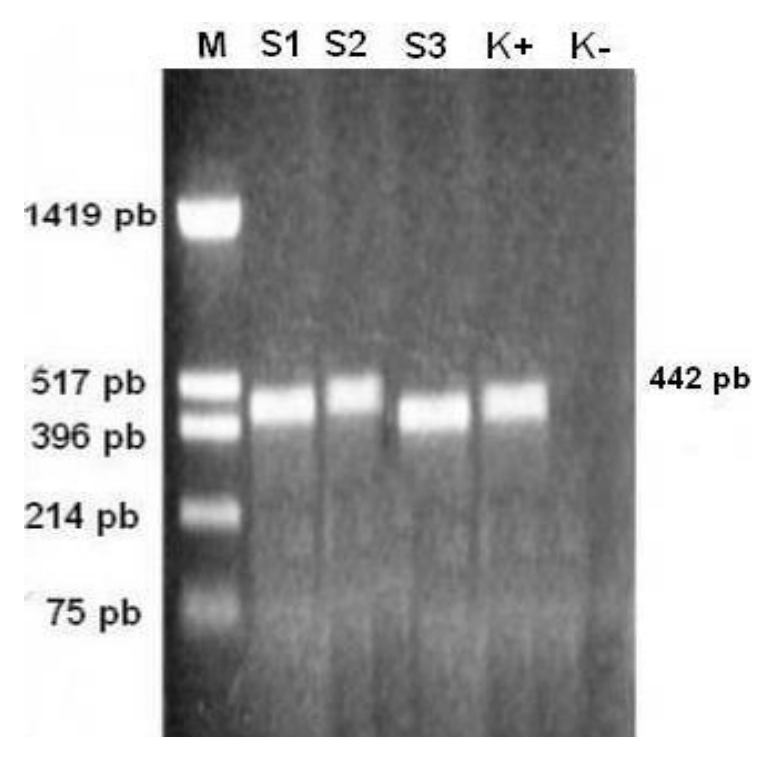

Gambar 1. Fragmen hasil PCR

Amplikon dipastikan bukan kontaminan karena hasil PCR kontrol negatip (K-) tidak menunjukkan adanya pita pada gel elektroforesis dan posisi pita sampel sejajar dengan kontrol positip (K+).

\section{Sel Rekombinan Hasil Kloning}

Proses kloning fragmen $0,4 \mathrm{~kb}$ mtDNA hasil PCR diawali dengan meligasikan fragmen mtDNA pada plasmid pGEM-T. Perbandingan molar antara pGEM-T dan fragmen DNA sisipan adalah 1:8. Hasil transformasi sel inang E.coli JM 109 oleh plasmid rekombinan diperoleh koloni ber-warna putih dan biru seperti yang tercantum pada tabel 1 .

Tabel 1. Hasil Transformasi E.coli JM109

\begin{tabular}{ll}
\hline Sampel & Jumlah Koloni \\
\hline S1 (Sampel 1) & 60 putih +24 biru \\
S2 (Sampel 2) & 50 putih +20 biru \\
S3 (Sampel 3) & 65 putih +26 biru \\
Kontrol positip & $>500$ koloni \\
Kontrol negatip & 0 koloni \\
\hline
\end{tabular}

Dari tabel 1 menunjukkan bahwa proses ligasi dan transformasi sel E.coli JM109 telah berhasil. Perbandingan jumlah koloni putih (sel rekombinan):biru (sel non rekombinan) adalah
2:1, hal ini menunjukkan proses transformasi berlangsung dengan baik. Koloni putih disebabkan gen lacZ pada vektor pGEM yang mengode enzim $\beta$-galaktosidase tidak berfungsi karena mengalami insersi DNA. Sebaliknya pada koloni biru terjadi karena adanya penguraian X-gal menjadi galaktosa dan 5bromo-4-kloroindigo (berwarna biru). Penguraian X-gal ini diinduksi oleh adanya isopropiltio- $\beta$-D-galaktosida (IPTG) dan dikatalisis oleh enzim $\beta$-galaktosidase yang dihasilkan oleh gen lac $Z$ yang tidak mengalami insersi DNA (Jones, 1998).

\section{Identifikasi DNA Plasmid Rekombinan}

Untuk mengidentifikasi adanya plasmid rekombinan dalam sel koloni putih dilakukan dengan metode pemotongan DNA plasmid oleh enzim restriksi PstI. Penggunaan enzim PstI karena sisi pemotongannya hanya satu dan terdapat pada bagian polycloning sites plasmid pGEM-T (promega, 1998) serta tidak memotong pada DNA insert.

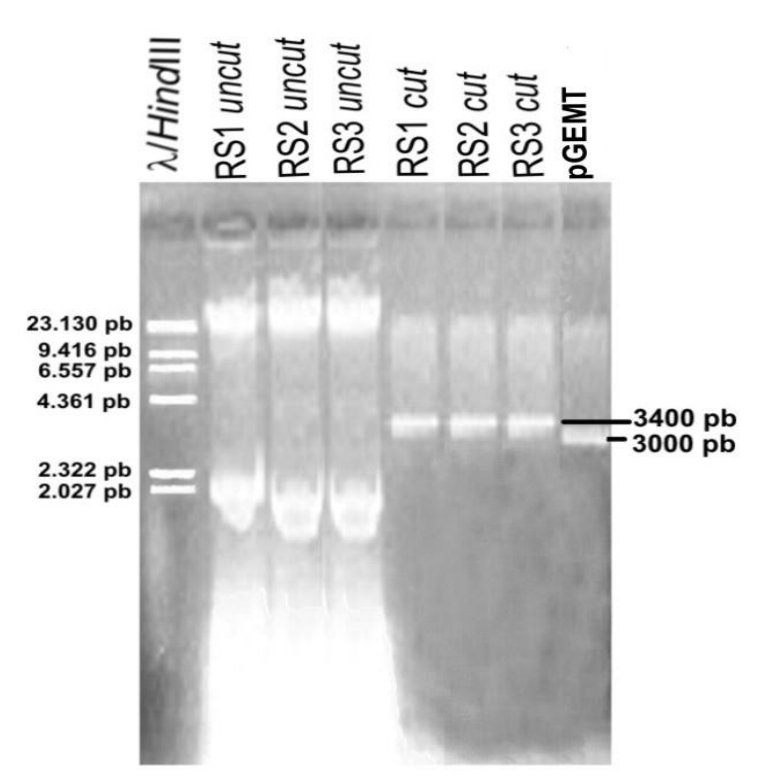

Gambar 2. Hasil restriksi DNA plasmid rekombinan dengan Pst $\mathrm{I}$ 
Hasil elektroforesis DNA hasil isolasi dari tiga koloni putih tanpa pemotongan enzim PstI (RS1, RS2, RS3 uncut) menghasilkan dua fragmen yaitu fragmen $>23 \mathrm{~kb}$ dan sekitar $2,1 \mathrm{~kb}$, seperti tercantum pada gambar 2. Fragmen $>23 \mathrm{~kb}$ adalah DNA kromosom sedangkan fragmen sekitar 2,1 kb diperkirakan adalah plasmid rekombinan yang masih dalam bentuk sirkuler. Untuk membuktikan bahwa fragmen tersebut adalah plasmid rekombinan maka harus dipotong dengan enzim PstI. Hasil elektroforesis DNA sampel yang sudah terpotong enzim Pst I diperoleh satu pita pada posisi sedikit di atas pita kontrol plasmid pGMT berukuran 3000 pb (3 kb), sehingga ukuran plasmid rekombinan diperkirakan sekitar 3400 pb (3,4 kb), jadi ukuran fragmen DNA insertnya adalah $0,4 \mathrm{~kb}$, sesuai dengan ukuran fragmen mtDNA hasil PCR. Berdasarkan pola restriksi enzim PstI tersebut dapat disimpulkan bahwa sel koloni putih yang diperoleh merupakan sel rekombinan. Sel rekombinan ini siap untuk digunakan pada penelitian selanjutnya, yaitu penentuan urutan nukleotida fragmen $0,4 \mathrm{~kb}$ mtDNA dengan metode sekuensing sehingga dapat diketahui identitas genetika dari sampel forensik yang dianalisis.

\section{DAFTAR PUSTAKA}

Anderson, S., Bankier, A.T., de Barrell, B.G., de Bruijn, M.H., Coulson, A.R., Drouin, J., Eperon, I.C., Nierlich, D.P., Roe, B.A., Sanger, F., Screier, P.H., Smith, A.J., Staden, R., and Young, I.G., 1981, Sequence and organization of the human mitochondrial genome, Nature, 290 (5806); 457-465.

Aquadro, C.F., and Greenberg, B.D., 1983, Human mitochondrial DNA variation and evolution; analysis of nucleotide sequences from seven individuals, Genet, 103; 287-312.
Cann, R.L., Stoneking, M., and Wilson, A.C., 1987, Mitochondrial DNA and human evolution, Nature, 325: 31-36.

Jones, P., 1998, Vectors Cloning Applicationsessential Techniques, John Wiley \& Sons, BIOS Scient Publishers, NewYork.

Moore, J.M. and Isenberg, A.R., 1999, Mitochondrial DNA Analysis of the FBI Laboratory, Forensic Science Communication, Vol. I, Number 2.

Noer, A.S., Martasih, F., Mulyani, S., Muktiningsih, dan Wirahadikusumah, M., 1994, Analisis Variasi Urutan Nukleotida D-loop mtDNA Manusia dari Berbagai Daerah di Indonesia, Proceeding Seminar Bersama UKM-ITB, I, 201-204.

Orrego, C., and King, M.C., 1990, Determination of familial relationships, di dalam PCR protocols a guide to methods and application, Academic Press, Inc. San Diego, California, USA.

Perkin Elmer, 1992, DNA Thermal Cycler; Users Manual, The Perkin Elmer Corporation, USA.

Promega, 1998, Technical Manual, pGEM-T and $p G E M^{\circledR}-T$ Easy Vector Systems, USA.

Sambrook, J., Fritsch, E.F. and Maniatis, T., 1989, Molecular Cloning: A Laboratory Manual, Vol. 1,2,3 Cold Spring Harbor Laboratory Press New York 